\section{Mathienzo. El punto justo entre la novedad y la tradición}

Mercedes Buey Fernández ${ }^{(1)}$

Resumen: Justo cuando se pensaba que el tema ya estaba agotado, y que obvios repetitivos resultaban los proyectos que invitan a enfocarse en el análisis de políticas y corrientes migratorias de los países periféricos hacia los centrales, toma fuerza una nueva mirada. La mirada desde el sur hacia el sur.

Los pueblos que olvidan sus tradiciones pierden la conciencia de sus destinos, escribió alguna vez Nicolás Avellaneda. Demostrar que la innovación puede respetar tradiciones y acoplarse de manera natural a mercados internacionales, es la mejor manera de preservación de identidad que encuentra el inmigrante.

Mathienzo, que nace de la combinación del vocablo Quechua Mathi, que significa calabaza o recipiente de calabaza, y la expresión rioplatense "tomarse unos matienzos", se convierte en cristalización del vínculo sur-sur.

El texto invita a analizar al mate no sólo como la expresión resultante de una construcción de identidad que late orgullosa en Sudamérica, sino que, alienta y promueve diferentes realizaciones que ayudan a la perdurabilidad de las tradiciones.

Palabras clave: migración - hemisferio sur - tradición - cultura - identidad - innovación diseño industrial - producción de objetos - mate - yerba mate.

[Resúmenes en inglés y portugués en las páginas 104-105]

(1) Diseñadora Industrial (UP). Ha sido profesora de la Universidad de Palermo en el Área de Diseño de Objetos y Productos de la Facultad de Diseño y Comunicación entre 2012 y 2018. A lo largo de su trayectoria se desempeñó como diseñadora senior y semi senior en diferentes empresas. Desde 2012 es socia gerente, diseñadora y fundadora de Estudio De Raíz y Yerba Mate Mathienzo, fue docente evaluadora de Proyectos de Graduación; es especialista en Gestión de Diseño (UBA) y asistente externa en el área de estudios ergonómicos y capacitaciones de diferentes empresas. 


\section{La Historia}

El mate es una infusión típica de los países de Sudamérica, obtenida de las hojas del Illex Paraguaiensis, principal legado de los aborígenes guaraníes. Ha echado profundas raíces en la región y es compartida por todos los estratos sociales. Con los años el mate se ha convertido en mucho más que una bebida, es símbolo de identidad, un rasgo cultural de identificación y al mismo tiempo, "evoca un ritual" (Pohjola, 2014)

La tradición del mate no puede analizarse o entenderse desde un único punto de vista ni evaluarse desde una mirada individual. Es un hecho social que excede lo personal y que no puede ser entendido sin referencia directa a la colectividad de la cual el sujeto es parte (Rubbi, 2017).

A pesar de que la región adoptó muchas formas colonizadoras europeas, el mate ha sobrevivido y se ha arraigado cada vez más como costumbre local. Si bien el mate comenzó siendo compartido en familia y se tomaba siguiendo ritos muy particulares, hoy en día el mate está presente en cualquier ocasión que así lo permita. Para los argentinos es un símbolo casi patrio, que pone orgulloso a cualquiera y que supone una excusa para encontrarse. De mano en mano, el mate se comparte en el círculo íntimo de la familia o con amigos, e incluso en el trabajo. Está presente en la cotidianeidad de la sociedad, y en todos los estratos sociales.

Representa la unión y el compartir, fortalece los vínculos, ayuda a la sociabilización, acorta distancias, relaja ambientes tensos y se acopla naturalmente a cualquier contexto. Dice Scutellá "el mate es compañero, amigo, gesto cordial y, otras veces, frente a un dilatado horizonte, se lo sorbe poco a poco, como tragos de una soledad infinita que se apodera del hombre argentino" (1989, p. 17).

El presente escrito busca reflexionar en torno al mate desde una mirada antropológica, y no tan técnica de la bebida en sí. Pretende analizar al mate como elemento de transmisión cultural y símbolo comunicacional, y al desarrollo de objetos que esta tradición dio lugar.

\section{El surgimiento}

En un comienzo los guaraníes adoraban la planta de la yerba mate. La consideraban un regalo de los dioses. Para este grupo, las hojas de yerba mate eran bebida, moneda de cambio y culto. Las infusionaban para beber, las fumaban y hasta las masticaban. Tenían incluso un ritual muy particular: al morir cualquier integrante de la comunidad, el grupo lo enterraba y plantaba sobre su tumba un árbol de yerba mate. Al crecer el árbol cosechaban e infusionaban sus hojas para beber mate en círculo alrededor del mismo, tal como se conforman hoy en día las rondas de mate. Consideraban así que el espíritu de esa persona fallecida viviría por siempre en sus corazones, al compartirse las hojas de su árbol (Barretto, 1989).

En tiempos de colonización, los conquistadores notaban que los guaraníes nativos tenían más resistencia durante las largas travesías en la selva luego de beber esta infusión. Observaban que entre sus armas llevaban una pequeña bolsa de cuero (guayacas) con hojas 
verdes trituradas y tostadas, y que las ponían en un pequeño cuenco de calabaza con agua y bebían filtrando con sus dientes o con una caña ahuecada (elemento que hoy conocemos como bombilla) y se disponían en círculos para compartirlo (Scutellá, 1989). Llamaban a la bebida Caiguá, kaá (yerba árbol selva) y (agua) gua (origen), algo así como agua de la yerba o agua de la selva. Más tarde nacería la expresión mate derivada del vocablo mati o mathi nombre en quechua que se le daba a la calabaza donde primero se preparaba la bebida (Lagier, 2008).

Si bien los jesuitas fueron los grandes propulsores de la yerba mate en la región sur del continente, y la comercialización de sus hojas fue la principal fuente de ingresos económicos durante la época de las misiones, fue tal el poder económico que se creó alrededor de la yerba mate, que incluso hoy se habla del oro verde. Determinó el asentamiento de ciudades, fue moneda de cambio durante la Colonia (un puñado de yerba que cupiera en una palma de mano abierta equivalía al pago por una jornada de trabajo) (Scutellá, p. 47, 1989).

El mate se enraizó de tal manera en la historia sudamericana, que a esta altura es casi imposible determinar el origen exacto de la costumbre. Es parte de la tradición y de la leyenda. Desde dioses vegetales, hasta regalos de sabios ancianos arrieros de la selva, son numerosos los mitos acerca del descubrimiento de la primera planta de yerba mate y surgimiento de la bebida como tal.

Pero, lo real es que, contada la historia como a uno más le guste, la costumbre aborigen de beber y compartir logró superar los tiempos de la colonización y adaptarse a los tiempos modernos. Lo interesante es observar como en todos los casos, la bebida se asocia con un regalo de los dioses (en mayor o menor medida) y se relaciona indefectiblemente con un fenómeno colectivo, casi nunca individual. Así es como, a pesar de lo absurdo o fantástico de estos mitos, representan de manera muy clara lo vivido en torno al mate y el momento de compartir. Invitan al análisis de los principios básicos de una sociedad y la vida en comunidad: ofrecer, compartir y mostrar solidaridad (Rubbi, 2018).

Lo concreto es que técnicamente el mate es un puñado de hojas secas infusionadas con agua caliente en un añejado recipiente donde dos o más personas beben de la misma bombilla sin siquiera limpiarla entre sorbo y sorbo. Sin embargo, el mate tiene un sabor distinto según el momento en que se lo tome. Es una tradición que supera costumbres. El mate une cualquier clase social, es un símbolo para expatriados, y significa conexión directa con su tierra, para el público nostálgico.

En estas experiencias observamos también una recuperación de algunos saberes ancestrales, resignificados en el marco del contexto actual globalizado, que se consideran, funcionan como un modo de reconfiguración de pertenencia comunitaria.

La tradición del mate es tan fuerte en Argentina, Paraguay, Uruguay y sur de Brasil, que cada uno tiene su propia fecha de celebración del día del mate. La bebida los identifica como un pueblo, como un colectivo, como un conglomerado nacional. El mate define su identidad e idiosincrasia. En resumen, el consumo del mate excede una práctica individual, y cumple un rol social determinante. Para algunos, el mate transmite fuerza, no sólo física, sino social y cultural (Pohjola, 2014). 


\section{El mate en Siria: sinónimo de transmisión cultural}

Si bien se sabe que en los países donde se han afincado importantes colonias argentinas como Estados Unidos y España, la exportación de yerba mate tiene cierta importancia, el consumo no sale de los círculos de expatriados o público nostálgico. Sin embargo, es fuerte la tendencia que existe en otros países donde los locales consumen mate por gusto. Por ejemplo, Siria, Líbano e Israel son los principales compradores de yerba mate argentina, y consumidores de mate por gusto.

En 2018 por ejemplo, Siria consumió 33 millones de kilos de los 43 totales exportados a Siria, Chile, Líbano, Estados Unidos y España (los 5 con más volumen) y otros países. (INYM, 2018) Hacia comienzos de siglo, entre 1850 y 1860 aproximadamente, llegó a la Argentina un importantísimo número de inmigrantes procedentes de Medio Oriente, sobre todo refugiados de la Guerra Civil Siria que se asentaban en la zona Noroeste del país. De esa multitud de inmigrantes, algunos se quedaron y otros no lograron adaptarse a la nueva tierra, pero lo cierto es que la mayoría se había aquerenciado con el consumo del mate. Los motivos seguramente sean variados e incomprobables, pero hasta el día de hoy la costumbre matera se sigue compartiendo de generación en generación.

Dentro de este grupo de inmigrantes, fueron los árabes, y especialmente los sirios, los que propagaron fuertemente la costumbre de tomar mate. Para ellos el mate se convirtió en una suerte de símbolo de supervivencia. Lo interesante es del caso es el análisis de los matices de cada mateada siria. Allí no infusionan la bebida en calabazas, sino que utilizan pequeños vasos (tamaño taza de café medida ristretto por ejemplo), y cada mateador cuenta con su kit de mate. Cada uno asiste a la ronda de mate con su bombilla en su saco o camisa, y el trabajo manual que se observa en ellas se considera una verdadera obra de orfebrería. Ello, en la Argentina no siempre ocurre, aquí la bombilla no necesariamente busca denotar un status particular. Otra característica es que allí lo que se gira en la ronda y se comparte el termo, no el recipiente (Scutellá, 1989).

\section{El diseño como vehículo de comunicación}

Los pueblos que olvidan sus tradiciones pierden la conciencia de sus destinos, escribió alguna vez Nicolás Avellaneda (s/f).

En este sentido, demostrar que la innovación puede respetar tradiciones y acoplarse de manera natural a mercados internacionales, es la mejor manera de preservación de identidad que encuentra el inmigrante.

De padres a hijos el mate pasa de generación en generación, el mate ha roto barreras impensadas y hoy no es raro verlo en cualquier mesa de trabajo; ha llegado a los vestuarios y campos de entrenamiento de la mano de personalidades mundialmente conocidas, y ha sido visto en camarines de estrellas internacionales. El hábito de beber ha evolucionado de tal manera, que de la intimidad del hogar, e incluso grupos cerrados de hombres con mujeres que sólo ingresaban a la habitación para cebar el mate, se ha pasado al espacio público y hasta a beberse mientras se realizan tareas como caminar o manejar. 
El mate marca tendencia, y las estadísticas de Google Trends por ejemplo, señalan un franco crecimiento del interés sobre esta bebida en países como Nueva Zelanda, ubicándolo dentro del top 50 a nivel mundial de países interesados en la temática (2019). Asimismo, ocupa el puesto 35 en el ranking de bebidas más tomadas en el mundo, según una lista confeccionada por el segmento especializado de CNN Travel, que incluye bebidas e infusiones de todo el mundo (Cheung, 2018).

Estos son sólo algunos ejemplos de cómo el hábito se ha expandido de los guaraníes a este tiempo de modo exponencial. El mate (objeto) se ha convertido en portador de cultura en sí mismo, y de ahí que el análisis por las realizaciones que ayudan a la perdurabilidad de esa tradición resulta de principal interés.

Mate con salvilla: mate típico de Perú (fines del siglo XVIII), mate construido íntegramente en plata o alpaca con una pequeña base en forma de bandeja dónde se colocaban pequeños bocados dulces o salados, para ser compartidos durante la ronda de mate. Algunos cuentos de la época dicen también que allí un enamorado clocaba una flor para su enamorada al momento de beberlo juntos.

Los mates con campanilla: mates de porcelana con un pequeño diseño silbador, que se accionaba para llamar la atención de la cebadora.

Mate inglés: los ingleses residentes en Argentina mandaban a hacer sus mates a Europa y los realizaban en porcelana, emulando la vajilla utilizada en los servicios de té inglés.

Loza de las monjas: similar al mate inglés, en Chile eran muy típicos los mates cerámicos con imágenes de la belle époque o niños con reminiscencias rococó.

Mate higiénico alemán: este tipo de mate es quizás el más curioso de todos por la originalidad del concepto y la funcionalidad del objeto. Al parecer este tipo de mate habría sido primeramente ideado por inmigrantes alemanes en la región, que, enamorados de la bebida, decidieron imprimirle su toque particular para compartir mate sin necesariamente beber todos de la misma bombilla. El mate higiénico como objeto no tenía precisamente una configuración formal de lo más atractiva, pero si evitaba que al agarrarlo uno se quemara la mano, contaba con una doble cámara y con una bombilla con boquilla de marfil intercambiable. La doble cámara evitaba la transmisión de calor a la mano, el doble fondo prevenía la filtración de cualquier partícula de polvo u hoja a través de la bombilla y hacia la boca del tomador.

Mate con tapita: en su mayoría este tipo de mates provenían de Perú o Bolivia y contaban con una pequeña tapa sujetada al cuerpo por medio de una cadena fina, y un pequeño orificio por donde pasaba la bombilla. Cada mate se servía tapado. Se cree que la intención primaria de la tapita era proteger al contenido de cualquier impureza que pudiera caerle durante los traslados por los polvorosos caminos que recorrían los gauchos. Otros escritos de la época dan cuenta de que en realidad era una excentricidad y una manera de lucir el objeto junto al facón amarrado en el cinturón.

Igual de interesante resulta el análisis de los accesorios, como la bombilla (takuapý en el idioma guaraní).

Contrariamente a lo que muchos pudieran pensar, el desarrollo de la bombilla fue bastante posterior al del mate. Tal como se comentó líneas más arriba, en un comienzo la bebida se infusionaba con agua no muy caliente en recipientes de calabaza y se filtraban las hojas directamente con los dientes superiores. Diferentes recopilaciones históricas dan cuenta 
de los primeros intentos de filtro, hasta su posterior evolución en bombilla tal como se usa hoy. Pasando por perforaciones directas en el recipiente, doble recipiente, un canuto de plata con boquilla, hasta una caña vegetal con crin de caballo y fibras duras en el extremo a modo de filtro (Scutellá, 1989).

En cualquiera de los casos, lo reconocible es que la variedad no estaba únicamente en el gusto, si no en los recursos y acceso a los diferentes materiales. La bombilla conceptualmente no esconde secretos, es un cilindro con perforaciones o filtro en la base. Sin embargo, cada cambio en su diseño significó un cambio en la evolución del elemento. Sin duda, el metal fue el material que impulsó el salto decisivo y a partir de allí las mejoras en el diseño, se dieron de manera vertiginosa hasta los modelos actuales. El achatamiento del pico para evitar el sobrecalentamiento o el quiebre en el tallo para poder tomar mate reclinado sin tener que inclinar el mate y volcar la preparación, o para beber manejando (de allí el famoso estilo de mate camionero); los desarrollos en pieza única, los avanzados diseños desmontables y con tornillo en la base para evitar obstrucciones.

Todos constituyen unidades demostrativas de diseño, que permiten enseñar la evolución del hábito, acompañado de un grupo de objetos que dan cuenta de la adaptación de estos a la cultura imperante. La cultura no modifica el hábito ni el hábito se impone en una cultura, ambas dimensiones dialogan de forma tal que la evolución es la única constante posible.

\section{De Argentina para el mundo: MATHIENZO}

La única región capaz de cultivar de manera natural la yerba mate es la comprendida por el noroeste de la Argentina, sur de Paraguay y sur de Brasil. Debido a las condiciones climáticas ideales de humedad y temperatura para el buen crecimiento de la planta, no existen al momento otras zonas tan fértiles a nivel mundial para el desarrollo de la bebida. Sin embargo, a pesar de esto, el mate es hoy una bebida conocida y consumida a nivel mundial, no sólo por sus propiedades como infusión, sino por su rol como lazo social. Esto constituye una oportunidad única para el actual y continuo desarrollo de mates y accesorios, de igual manera que hacían los gauchos de antaño.

Hoy en día existe una amplia variedad de mates y, en cuanto a material se refiere, los hay de vidrio, caña, cerámica, aluminio, madera plástico e incluso silicona. Las tipologías actuales son variadas, tal como los pequeños guiños de diseño.

Empujados por esta tendencia nace en 2012 Mathienzo. El nombre surge de la combinación de la voz quechua mathi y la expresión lunfarda tomar unos matienzos.

La motivación de los diseñadores de la marca era clara: satisfacer las necesidades insatisfechas de los nuevos grupos de consumidores en busca de sentido y carentes de productos que los identifiquen y les brinde ese reconocimiento que tanto buscaban.

Mathienzo no se originó para mostrar una nueva idea, se concibió con el objetivo de romper cualquier esquema en el rubro tradicional de la yerba, sentando las bases del éxito en el diseño de experiencias.

En primera instancia Mathienzo fue simplemente el nombre de un mate de silicona que echaba por tierra cualquier prejuicio que existiese en torno a la innovación en un mercado 
clásico y tradicional, demostrando que el buen diseño podía ser disruptivo, sin abdicar de tipologías conocidas y sin faltarle el respeto a ninguna cultura.

Prontamente el producto ganó visibilidad y logró afianzarse como referente dentro de ese grupo de nuevos consumidores, ávidos de cambio y en busca de identificación, y se convirtió en marca propia. Actualmente el diseño de ese primer mate de silicona se acompaña con una línea propia de yerba mate premium, dos otras variedades de mate en cuero y madera, bolsos de cuero y principalmente diferentes propuestas de experiencia en torno al mate y la tradición matera.

Enfocados siempre en conectar esa tradición tan argentina con el mundo, Mathienzo comenzó a ser exportada, potenciando la transmisión cultural, y sirviendo como vehículo de comunicación y transmisión de ADN argentino al mundo. Actualmente se exporta a Rusia (y 7 países periféricos), Australia, sur de Chile, Alemania y desde allí resto de Europa. Lo interesante del caso es que de primera medida reconocieron que para salir al mundo y ganar mercados internacionales, debían adaptarse a aquellas culturas que buscaban conquistar, entendiendo y transformándose continuamente. En este sentido, Mathienzo es entonces otro buen ejemplo de como un objeto se vuelve excusa para conectar, transmitir culturas y compartir costumbres, cristalizando un vínculo y preservando la identidad de los grupos, a través de los objetos. Reconocer el compartir tradicional como oportunidad de diseño es parte del éxito de la marca.

La elección de los materiales no fue una azarosa, pues eran mucho mejor reconocidos a nivel mundial que las calabazas tradicionales.

Asimismo, de la línea tradicional de yerba mate se desprendió otra propuesta, la línea de Botánicas. Esta es una línea de blends de yerba mate con incrustaciones de pétalos y semillas naturales. De nuevo, otro ejemplo de búsqueda de expansión internacional, atendiendo a las culturas particulares. Esta línea se asemeja a la de los tés indios, o demás infusiones orientales.

\section{Visión de género}

La innovación honesta es el motor de cambio en este presente. Y los consumidores conscientes tienen el poder de exigir y optar por productos de mayor valor agregado e impacto. La apertura revela exigencias que deben acomodarse a estos nuevos horizontes que hasta hace poco se definían del sur hacia el norte y ahora lo hacen en la misma latitud.

Definido incluso por el INYM: pensar en nuevo, pensar en introducir novedades con el fin de mejorar el producto y el sector es determinante para el crecimiento económico de la región, y constituye la cristalización del vínculo sur-sur (2019).

Del mismo modo, el impacto que las migraciones tienen en cada región supone un desafío para las economías locales y frente a esto se incrementa el reconocimiento de los saberes locales y valores ancestrales como medio para el desarrollo económico, ambiental y personal. En este sentido, el enfoque de género permite evidenciar la modificación de roles, y la existencia de perfiles que escapan al estereotipo de esposa que acompaña al marido mo- 
tivada por una "reagrupación familiar" y en cambio, lo hace escapando de la pobreza o condiciones estructurales de violencia. (Tornay, 2016)

Actualmente, la feminización de las migraciones y la necesidad de reconocer el rol de importancia que las mujeres han jugado en las transferencias y mercantilización de la cultura, implica pues, hablar de la vulnerabilidad que las envuelve y también la posible resistencia al proceso.

En Tavapy, Departamento paraguayo de Alto Paraná, existe un grupo de mujeres que son un ejemplo de lo mencionado anteriormente. El colectivo cosecha yerba mate como medio de subsistencia, pero también en resistencia a la migración forzada. La Asociación Mujeres Virgen Del Rosario, incursiona en el cultivo y para evitar el desarraigo local. Son unas 28 mujeres cabeza de familia que le hacen frente al desafío de la capacitación y la expansión comercial.

El proyecto no sólo brinda sustento, sino que, promueve el arraigo y oportunidades de competir en mercados muy exigentes, brindando oportunidades a más de 300 familias productoras. A su vez, el proyecto se reconoce como uno de triple impacto: económico, social y ambiental. Productos de calidad, que ayudan al arraigo de comunidades locales, y una conciencia ambiental de la mano del cultivo en el bosque, barrera protectora contra las fumigaciones de los campos de soja, y protector térmico natural de plantas medicinales (Aquino, 2017).

Como se puede observar, y a pesar de que la información dura es irregular y mucho menos completa que los de los flujos sur-norte, la migración sur-sur no es un fenómeno nuevo, y representa un porcentaje nada despreciable y sugiere que "el stock de migrantes sur-sur es grande y económicamente importante" (Ratha y Shaw, 2007).

De hecho, es una de las principales prioridades para la investigación en el campo de la migración.

\section{Reflexión final}

En el presente escrito se ha visto que más allá de la información dura en torno a la cuestión migratoria, y la discusión moderna entre la visión optimista y la pesimista del tema, prevalece el enfoque positivo.

Se ha visto también que la migración internacional es un fenómeno constante y dinámico y refleja etapas del desarrollo por las que atraviesan los países. En este sentido, pretender comprender enteramente las múltiples interacciones que existen entre las migraciones y el desarrollo requiere contemplar no únicamente el nivel de desarrollo del país de origen y del receptor, sino, motivaciones y características cada vez más diversificadas (Villareal, 2017). Al igual que sus consecuencias duales y a veces contradictorias, superando al modelo de análisis binario del asunto. Sobre todo, en un momento en que existen más de 247 millones de migrantes que representan el 3,4\% de la población mundial (Ratha y Shaw, 2007).

En segundo lugar, si bien la literatura acerca de las migraciones Sur-Sur es, en proporción, escasa comparada con aquellas de Sur-Norte o Norte-Norte, casos como el de Mathienzo 
o la Asociación Mujeres Virgen Del Rosario, muestran que las migraciones internacionales pueden ser un vector de desarrollo, y sus productos cristalización de ese vínculo Sur-Sur. En este sentido, la visión optimista que se apoya en la propuesta de codesarrollo y enfatiza en las ventajas mutuas que los desplazamientos suponen en términos económicos, sociales y culturales da sustento a las ideas expuestas anteriormente.

Esta fórmula, pergeñada por Sami Naïr se trata de una propuesta para integrar migración y desarrollo de tal manera que ambos países (el de origen y el receptor) puedan beneficiarse de los desplazamientos, enfatizando en estas ventajas mutuas, en términos económicos, sociales y culturales. Algo así como una forma de "relación consensuada ente dos países de forma que el aporte de los inmigrantes del país de acogida no se traduzca en una pérdida para el país de envío" (Naïr, 1997, s/p).

Lo interesante está en que deposita en el stock de migrantes el protagonismo casi absoluto durante todo el proceso. El modelo propone buscar activamente el involucramiento del grupo en la promoción de proyectos de mejoría de las condiciones sociales y económicas de sus localidades de origen y destino (Giménez, 2010).

Esa misma fue la motivación de Mathienzo al decidir explorar el mundo. Ser objeto de comunicación, abrazando la paradoja de que la acción transformadora tendría lugar cruzando fronteras, pero que esto indefectiblemente potincaría lo local, ampliando el espectro de actores involucrados y dando lugar a un proceso trasnacional con alto potencial de desarrollo.

\section{Listado de Referencias Bibliográficas}

Aquino, L. (2017). Asociación de Mujeres da un gran paso para la producción de yerba mate para mercados exigentes. Recuperado el 20/6/19. Disponible en: http://www.wwf.org. py/?299270/Asociacin-de-Mujeres-da-un-gran-paso-para-la-produccin-de-yerba-matepara-mercados-exigentes

Barretto, M. (1989). El mate, su historia y cultura. Buenos Aires: Editorial del Sol.

Cheung, T. (2018). World's 50 most delicious drinks. Recuperado el 23/6/19. Disponible en: https://edition.cnn.com/travel/article/most-delicious-drinks-world/index.html

Giménez, C. (2010). A favor del codesarrollo. Una llamada al diálogo y a la cooperación. Prólogo en Lacomba, J. y Flomir, F. De las migraciones como problema a las migraciones como oportunidad. Madrid: La Catarata. Publicado en: Villareal, M. (2017). Replanteando el debate sobre migraciones internacionales y desarrollo: nuevas direcciones y evidencias. Brasilia: Remhu. Disponible en: http://www.scielo.br/pdf/remhu/v25n51/1980-8585-remhu -25-51-181.pdf

Google Trends (2019). Exporar: Mate. s/f. Recuperado el 20/6/19. Disponible en: https:// trends.google.com.ar/trends/explore?q=mate

Instituto Nacional de Yerba Mate (2019). Se recuperan las exportaciones. Recuperado el 18/6/19. Disponible en: https://www.inym.org.ar/se-recuperan-las-exportaciones-y-elconsumo-interno-mantiene-la-tendencia-positiva/ 
Lagier, J. (2008). La Aventura de la Yerba Mate, Más de cuatro siglos de Historia. Buenos Aires: INYM. (La Aventura de la Yerba Mate, Más de cuatro siglos de Historia, Jerónimo Lagier). Naïr, S. (1997). Informe de balance y orientación de la política de codesarrollo en relación a los flujos migratorios, Paris, 1997. En: Cortés, A. (2006). Migración y codesarrollo: una propuesta innovadora. Madrir: Imprefepp.

Pohjola, J. (2014). Mate: Bebida energizante de Sudamérica. Finlandia: s/n 2019. Recuperado el 22/6/19. Disponible en: https://www.elterritorio.com.ar/el-mate-representa-unautopia-un-modelo-ideal-de-relacion-social-9527963645305392-et

Pohjola, J. Mate - Etelä-Amerikan Voimajuoma (Mate, energetical southamerican beberage). Finland : s.n., 2013.

Ratha, D. y Shaw, W. (2007). South-South Migration and Remittances. Documento de Trabajo del Banco Mundial, n. 102, Washington, DC, 2007. Recuperado el 12.11.19. Disponible en: http://siteresources.worldbank.org/INTPROSPECTS/Resources/334934-1110315015165/ SouthSouthMigrationandRemittances.pdf

Ratha, D. y W. Shaw. (2007). South-South migration and remittances. World Bank Working Paper No. 102. Recuperado el 12/11/19. Disponible en: http://siteresources.worldbank. org/INTPROSPECTS/Resources/334934-1110315015165/SouthSouthMigrationand Remittances.pdf

Rubbi, L. N. (2018). The Anthropology of Mate. Recuperado el 22/6/19. Disponible en: https://www.estadointernacional.com/the-anthropology-of-mate/

Scutellá, F.N. (1989). El mate. Bebida nacional argentina. Buenos Aires.: Industria Gráfica del Libro.

Tornay, M. C. (2016). Migración femenina en mesoamérica: mujeres haciendo camino. Recuperado el 30/6/19. Disponible en: http://www.revistapueblos.org/blog/2016/12/14/ migracion-femenina-en-mesoamerica-mujeres-haciendo-camino/

Villareal, M. (2017). Replanteando el debate sobre migraciones internacionales y desarrollo: nuevas direcciones y evidencias. Brasilia: Remhu.

Abstract: Just when it was thought that the issue was already exhausted, and that obvious and repetitive projects were inviting everybody to focus on the analysis of migratory policies and flows from the central countries to the central ones, some are looking with fresh eyes. The ones set from the south to the south.

People who forget their traditions lose the awareness of their destinies, once wrote Nicolás Avellaneda. Demonstratrating that innovative products can still be respectful with traditions and fit naturally into international markets, is the best way immigrants have to preserve their identity.

Mathienzo, born from the combination of the Quechua word Mathi, meaning pumpkin or pumpkin container, and the Rioplatense expression, let's share some matienzos, becomes the crystallization of the south-south bond. 
The text invites to analyze mate not only as the expression resulting from an identity construction that beats proud in South America, but encourages and promotes different achievements that help the durability of traditions.

Keywords: migration - global south - tradition - culture - identity - innovation - industrial design - object production- mate - yerba mate.

Resumo: Quando já o tema parecia esgotado e os projetos que convidam a focar na análise de políticas e correntes migratórias dos países periféricos para os centrais pareciam óbvios e reiterativos, um novo olhar ganha força. O olhar do sul para o sul.

"Os povos que esquecem suas tradições perdem a consciência do seu destino" escreveu alguma vez Nicolás Avellaneda. Demonstrar que a inovação pode respeitar tradições e ajustar-se de forma natural a mercados internacionais, é a melhor maneira de preservar a identidade que encontra o imigrante.

Mathienzo, que surge da combinação do vocábulo Quechua Mathi que significa cabaça ou cuia e a expressão rio-platense "tomar alguns matienzos" se transforma na cristalização do vínculo sul-sul.

O texto é um convite para analisar o chimarrão não apenas como a expressão resultante de uma construção de identidade que late orgulhosamente em Sul América mas também como forma de alentar e promover diferentes realizações que ajudam à manutenção das tradições.

Palavras chave: migração - hemisfério sul - tradição - cultura - identidade - inovação desenho industrial - produção de objetos - mate - erva mate.

[Las traducciones de los abstracts fueron supervisadas por el autor de cada artículo] 